\title{
Monitoring Landscape Change for LANDFIRE Using Multi-Temporal Satellite Imagery and Ancillary Data
}

\author{
James E. Vogelmann, Jay R. Kost, Brian Tolk, Stephen Howard, Karen Short, \\ Xuexia Chen, Associate Member, IEEE, Chengquan Huang, Kari Pabst, and Matthew G. Rollins
}

\begin{abstract}
LANDFIRE is a large interagency project designed to provide nationwide spatial data for fire management applications. As part of the effort, many 2000 vintage Landsat Thematic Mapper and Enhanced Thematic Mapper plus data sets were used in conjunction with a large volume of field information to generate detailed vegetation type and structure data sets for the entire United States. In order to keep these data sets current and relevant to resource managers, there was strong need to develop an approach for updating these products. We are using three different approaches for these purposes. These include: 1) updating using Landsat-derived historic and current fire burn information derived from the Monitoring Trends in Burn Severity project; 2) incorporating vegetation disturbance information derived from time series Landsat data analysis using the Vegetation Change Tracker; and 3) developing data products that capture subtle intra-state disturbance such as those related to insects and disease using either Landsat or the Moderate Resolution Imaging Spectroradiometer (MODIS). While no one single approach provides all of the land cover change and update information required, we believe that a combination of all three captures most of the disturbance conditions taking place that have relevance to the fire community.
\end{abstract}

Index Terms-Landscape monitoring, LANDFIRE, Landsat, MODIS, time series analyses.

\section{INTRODUCTION}

$\mathbf{I}$ N RESPONSE to the many large and severe fires that occurred in the United States during the latter part of the twentieth century, the United States Secretaries of Agriculture and Interior developed the National Fire Plan in August 2000 [1]. This plan covers a wide array of fire-related issues, including ensuring sufficient wildland firefighting capacity in the future, rehabilitating landscapes affected by wildland fire, reducing hazardous wildland fuel, and providing assistance to communities

Manuscript received October 30, 2009; accepted February 01, 2010. Date of publication April 12, 2010; date of current version May 20, 2011. The work of J. Kost and B. Tolk was supported by USGS Contract 08HQCN0005. The work of X. Chen and K. Pabst was supported by USGS Contract 08HQCN0007.

J. E. Vogelmann, S. Howard, and M. G. Rollins are with the USGS Earth Resources Observation and Science (EROS) Center, Sioux Falls, SD 57198 USA.

J. R. Kost and B. Tolk are with Stinger Ghaffarian Technologies, USGS Earth Resources Observation and Science (EROS) Center, Sioux Falls, SD 57198 USA.

K. Short is with Systems for Environmental Management, Missoula, MT 59801 USA.

X. Chen and K. Pabst are with the ASRC Research and Technology Solutions (ARTS), USGS Earth Resources Observation and Science (EROS) Center, Sioux Falls, SD 57198 USA.

C. Huang is with the Department of Geography, University of Maryland, College Park, MD 20742 USA.

Color versions of one or more of the figures in this paper are available online at http://ieeexplore.iee.org.

Digital Object Identifier 10.1109/JSTARS.2010.2044478

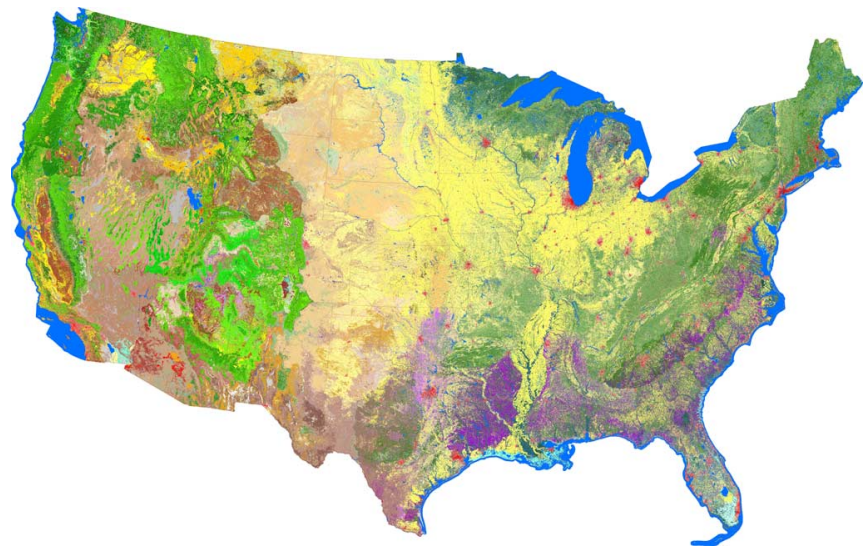

Fig. 1. LANDFIRE existing vegetation data set developed for the conterminous United States. Different shades of green and purple represent different types of forest cover. Shades of tan, brown and orange represent rangeland and grassland ecosystems. Light yellow represents agriculture, red represents urban, and blue represents water.

affected by wildland fire. To help meet some of the goals in the National Fire Plan, it was critical that managers and the public have access to up-to-date consistent and comprehensive nationwide geospatial data for identifying and prioritizing landscapes at high risk from wildland fires. Except from a few relatively localized areas, such geospatial data did not exist when the Plan was developed.

To help address some of these concerns, the LANDFIRE project, or Landscape Fire and Resource Management Planning Tools Project, was chartered in 2004 [2]. The first rendition of LANDFIRE, completed in 2009, produced spatial data describing vegetation type and structure, wildland fuel, fire regimes, and a range of other data sets for the entire United States [3]. The vegetation-type data set shown in Fig. 1 illustrates one of the completed LANDFIRE products. In this paper, we will confine our discussion to the processes related to vegetation type and structure development. These data sets are important foundation data layers for deriving many of the other LANDFIRE data layers, particularly the wildland-fire fuel and fire regime products.

Vegetation-type and structure data layers developed for LANDFIRE were based primarily on analysis of circa 2000 vintage Landsat Thematic Mapper (TM) and Thematic Mapper Plus (ETM+) images that were part of the MultiResolution Land Characteristics (MRLC) collection [4]. It is not our intent to describe in detail the methods used to create the national vegetation data layers, but a few key points are pertinent: 1) three dates of imagery (spring, summer and fall) were used 
to train classification models; 2) classification data sets were developed via supervised classification using decision and regression tree approaches [5];3) a database consisting of several hundred thousand georeferenced field points, known as the LANDFIRE Reference Database (LFRDB), was used to train the algorithms; 4) the existing vegetation legend was based on NatureServe's Ecological Systems classes, which represents a nationally consistent midscale classification of vegetation units [6]; 5) the vegetation structure data included canopy density (binned into 10 percentage classes) and canopy height (binned into several classes, depending on life form type); and 6) a large number of "ancillary" spatial data sets were used to develop the final data products, including data from the National Land Cover Database [7], digital elevation model data, and soils data.

The development of the LANDFIRE vegetation data layers required a full time team of over ten individuals representing fields of geography, ecology, and computer science, and the project took about five years to complete. As such, it is not the type of endeavor that one would consider doing annually, or even biennially. Nonetheless, potential users of the LANDFIRE data expressed concern early on in the project that the data sets being developed would be "out-of-date" for their areas of interest. Thus, it became evident at an early stage of the project that in order for LANDFIRE to be relevant to many users for a long period of time, we would need to develop methods and approaches that would enable us to update the data sets on a regular basis, and thus keep the data sets current and relevant.

In fact, the LANDFIRE Executive Charter (available at http://www.landfire.gov/) already had a provision for updating the LANDFIRE project to regularly update data products. This directive is, and will be, instrumental in transitioning LANDFIRE from a project to a program and its implementation will be imperative for maintaining the timeliness and quality of products as the landscape changes. The general update schedule for the LANDFIRE Program will be at biannual and decadal intervals with the first update scheduled for completion by October, 2010. Biannual updating will involve modifying the original LANDFIRE data sets with interannual disturbance information (i.e., updating just those areas that have been determined to have undergone recent changes), while decadal "updating" is likely to consist of major remapping activities.

Recently the USGS began providing Landsat imagery to users over the Internet at no cost [8], which effectively ended an era whereby Landsat data charges severely limited the scope and types of land-cover projects that could be undertaken. Until recently, the generation of any type of Landsat-based wall-to-wall US land-cover data set renewed annually would most likely have been considered cost prohibitive, impractical and untenable. Although Landsat data cost is no longer a barrier to implementing large-area operational land-cover monitoring projects, many other major challenges remain.

The LANDFIRE updating process, hereafter referred to as Remote Sensing of Landscape Change (RSLC) has four main elements. These are: 1) acquisition and compilation of field data; 2) wildfire burn mapping, as being done by the Monitoring Trends in Burn Severity (MTBS) project; 3) updating and analysis using the Vegetation Change Tracker (VCT [9]); and 4) mapping and incorporation of subtle intra-state changes, such as those related to insects and disease. In this paper, one of our objectives is to report the progress that we have made towards developing an operational land cover monitoring capacity with the LANDFIRE. While there is still much research to be done, the first three elements are reasonably well developed and are approaching operational status, whereas the fourth (related to insects and disease) is still largely in the research and development phase. In addition to providing some of our positive results, we will also share some of the challenges and potential problems that we foresee.

\section{FIELD DATA}

LANDFIRE mapping was supported by a vast database of field-sampled information, known as the LANDFIRE Reference Database (LFRDB). This and newly acquired field information continues to be an integral part of the RSLC effort. The LFRDB currently comprises vegetation and fuel data from approximately 800,000 geo-referenced sampling units located throughout the United States. These field data were amassed by capitalizing on the existing information resources of outside entities, such as the USFS Forest Inventory and Analysis (FIA) Program, the USGS National Gap Analysis Program, and state natural heritage programs. Vegetation data drawn from these sources for use in LANDFIRE include natural community occurrence records, estimates of canopy cover and height per plant taxon, and measurements (e.g., diameter, height, crown ratio, crown class, density) of individual trees. Fuel data include biomass estimates of downed woody material, percentage cover and height of shrub and herb layers, and canopy base height estimates. Digital photos of the sampled units are archived, when available. While we will touch on some key points here, Toney et al. [10] explain in detail how these types of field data, specifically those collected by FIA, have been acquired, incorporated into the LFRDB, and used in LANDFIRE.

Existing programs such as FIA have afforded LANDFIRE a wealth of useful data from forested systems including relevant measurements of millions of individual trees. Data from non-forest systems have proven less readily available. To help fill apparent gaps in data coverage, LANDFIRE field crews were dispatched in the early stages of the national effort to collect data following The Fire Effects Monitoring and Inventory Protocol (FIREMON) [11] in target areas. Efforts remain underway to acquire data from underrepresented areas and vegetation types and to incorporate additional records that will help inform LANDFIRE updates and enhance our monitoring capacity, including re-measurements of sites already in the LFRDB. At present, the FIA Program is a key source of these repeated measures. We are currently looking to additional monitoring efforts with permanent sampling arrays, particularly in rangelands, to augment the re-measurement data in the LFRDB as well as exploring use of the USFS Fire and Fuels Extension to the Forest Vegetation Simulator (FVS-FFE) [12] as a tool to model the development of stands that have not been repeatedly sampled in the field. Inputs for FVS-FFE can be generated by querying the LFRDB.

To meet all of the needs of LANDFIRE, several key attributes must be systematically derived from the acquired data and also included in the LFRDB. These attributes include existing and 
potential vegetation type in the form of NatureServe's Ecological Systems [6], [10], tree canopy cover and height predicted from spatially explicit empirical models [13], uncompacted crown ratios [14], and several canopy fuel metrics (e.g., bulk density) derived from the FuelCalc program [15]. At various stages in data compilation, including after the attribution of Ecological Systems, records are carefully screened for information or spatial errors. Questionable data are either identified accordingly or removed from the LFRDB, depending on confidence in the assessment. The remaining data points are then associated with a number of ancillary datasets via a series of spatial overlays. These datasets include the Landsat image suite, the National Land Cover Database [7], the digital elevation model and derivatives [16], soil depth and texture layers [17], and a set of 42 simulated biophysical gradient layers (e.g., evapotranspiration, soil temperature, degree days). The latter are generated using WX-BGC, an ecosystem simulator derived from BIOME-BGC [18] and GMRS-BGC [19]. The extracted values from each of these overlays are archived in the LFRDB for potential use as predictor variables in the mapping process.

In 2008, LANDFIRE began developing a geodatabase augmenting the LFRDB to accommodate field records of treatments, disturbances, and other events that have considerably altered vegetation or fuel conditions since 1999, and which must be accounted for to accurately update the 2000-vintage LANDFIRE data. As with the LFRDB, this new "Events" database draws heavily upon the existing information resources of outside programs, such as the USFS Forest Activity Tracking System. Attributes that must be associated with each event include a brief description of the occurrence and the year in which it occurred. Additional information sought, but not required, includes an indication of the severity of each event. The bulk of the viable data acquired to date have come from federal agencies, which often archive their fire and other activity records in public or corporate clearinghouses. Geospatial records of non-wildfire activities taking place on non-federal lands, particularly private holdings, are proving harder to come by and are relatively few in the LANDFIRE Events database.

\section{Monitoring TREndS IN BURn SEVERITY}

\section{A. General Overview}

Sponsored by the Wildland Fire Leadership Council (WFLC), the Monitoring Trends in Burn Severity (MTBS) project is a five-year effort that commenced in 2006. The project was initiated in response to a General Accounting Office recommendation to develop and implement a standardized, comprehensive approach to assess burn severity across the various land management agencies. It was also initiated to monitor the effectiveness of the National Fire Plan and Healthy Forest Restoration Act. A major goal of the project is to provide nation-wide baseline information to assess synoptically the environmental impacts and trends of fire. Fire is a major agent of landscape change, especially throughout the western and southeastern United States, and the MTBS data sets are an important component of RSLC.

Many previous investigations have shown the utility of satellite-based multispectral data to assess and monitor ecosystems

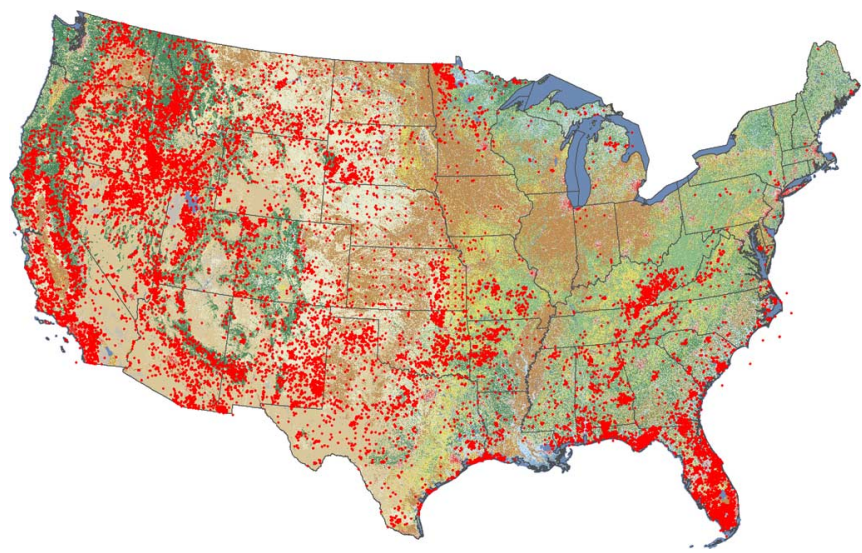

Fig. 2. Fire Occurrence Database recorded fires (1984-2008) in the lower 48 states. The large fires were mapped by the Monitoring Trends in Burn Severity project. Note mis-located fires in Atlantic Ocean and number of fires reported between TX and NM.

[20]-[23]. Assessing the severity of present-day fires is feasible using a number of existing satellite platforms, but due to limited spatial extent and temporal depth, providing a comprehensive historical baseline of detailed information using some of these platforms is not possible. The MTBS project was implemented to take advantage of satellite-based techniques, advances in computing capacity, and the existing long-term archive of Landsat satellite data covering the United States. The project is a joint effort between the US Forest Service's Remote Sensing Applications Center (RSAC) and the US Geological Survey's Earth Resources Observation and Science Center (EROS) Center, and its mandate is to map the severity of all "large" fires that have occurred in the United States since 1984. "Large" is defined as greater than 1000 acres in the western US, and greater than 500 acres in the eastern US.

For the MTBS project, "burn severity" refers to the effects of fire on the above-ground biomass. This definition is adapted from that of the term "fire severity" in the National Wildfire Coordination Group (NWCG) Glossary of Wildland Fire Terms [24]: "Degree to which a site has been altered or disrupted by fire; loosely, the product of fire intensity and residence time." Furthermore, burn severity is presumed to: 1) occur on a gradient; 2) manifest as a mosaic within a fire perimeter; and 3) be "mappable" using remote-sensing techniques.

\section{B. Fire Occurrence Database}

An integral component of the MTBS project is a comprehensive fire-occurrence database (FOD). This information supports the effort to identify appropriate Landsat imagery. Over 28,000 historical fire records (1984-2008) from all federal land management agencies along with comparable information from states have been compiled into a FOD providing information on fire locations and dates. This database has some imperfections, including duplication of fire data points and geospatial errors, but despite these occasional problems, the data base is a valuable starting point for MTBS mapping. Locations of 25,700 fires included in the FOD for the conterminous US are shown in Fig. 2. 


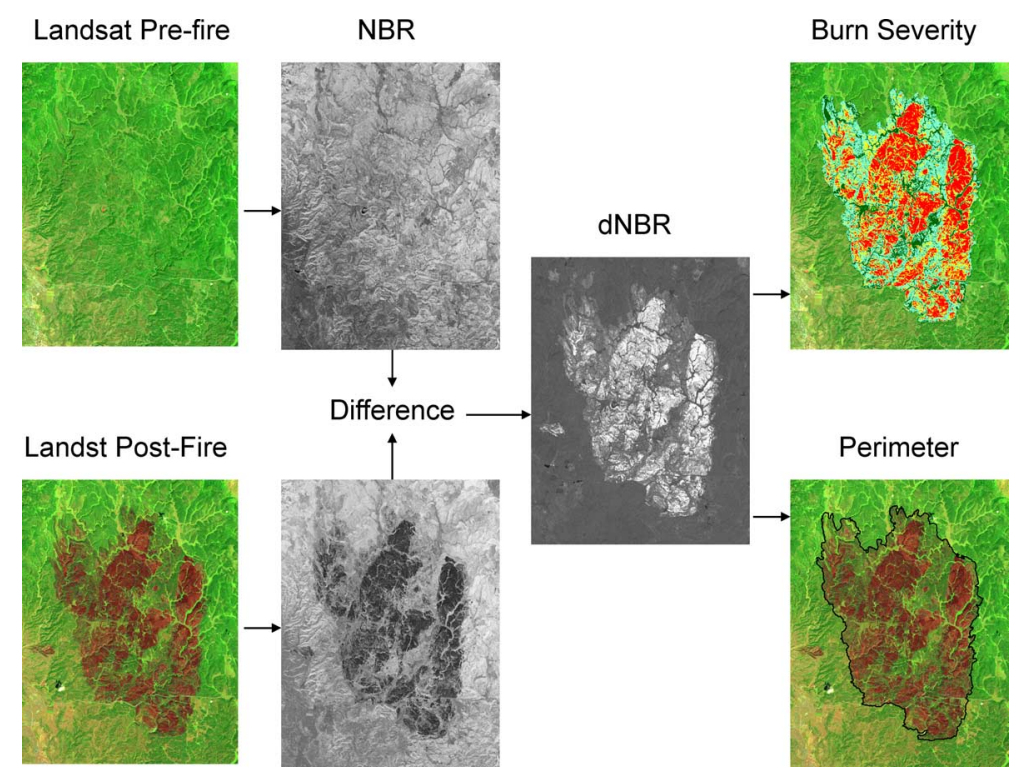

Fig. 3. Example of monitoring trends in burn severity mapping process.

\section{Assessment Strategies}

The MTBS project is based upon the USGS archive of Landsat TM and ETM+ imagery dating back to 1984. Using the fire location, date, and assessment strategy as a guide, imagery from the archive is selected for analysis. Because a fire occurs at a "moment" in time, selecting the best imagery to capture its effects is an important consideration. The MTBS project draws upon three different assessment strategies: 1) extended assessment (EA); 2) initial assessment (IA), and 3) single-scene assessment. For both EA and IA, images from two dates (one prefire and one postfire) are compared to assess fire severity. For EA, the post-fire image is selected to represent the "peak of green" during the next growing season. By this means, some delayed mortality can be accounted for in the assessment. This approach is generally used for forest and some shrubland fires. For IA, the postfire image is selected to represent conditions soon after the fire is out. This approach is used for some shrubland and grassland fires when the fire scar vanishes quickly due to vegetation recovery or weathering. Single-Scene Assessment is done sparingly, and only when suitable prefire imagery is not available, commonly due to cloud cover. For any two-scene assessment (EA or IA), it is important to match the phenology and illumination geometry of the scenes as best possible in order to assess changes due to fire, not changes due to seasonality or other temporal artifacts.

\section{Image Processing}

All imagery is precision terrain corrected and calibrated to at-satellite reflectance. Thematic Mapper and Enhanced Thematic Mapper + data sets are preferred in part because the second shortwave infrared band (Band 7; 2.08-2.35 $\mu \mathrm{m}$ ) from this source has been found to be very effective for burn mapping. Using an algorithm similar to the Normalized Difference Vegetation Index (NDVI), band 7 is combined with the near infrared band (Band 4; 0.76-0.90 $\mu \mathrm{m}$ ) to derive the normalized burn ratio (NBR):

$$
\mathrm{NBR}=\frac{(\text { Band } 4-\text { Band } 7)}{(\text { Band } 4+\text { Band } 7)}
$$

Burn severity is determined after the pre-fire and post-fire images are selected, NBR data sets are generated, and difference images are calculated from the pre- and post-fire NBR data sets (dNBR; Fig. 3):

$$
\mathrm{dNBR}=\text { Prefire NBR-Postfire NBR. }
$$

\section{E. Burn Severity Assessment}

Relatively high dNBR values in the resulting spatial data sets are interpreted as areas of vegetation loss. In other words, burn severity mapping as described here rests on the assumption that higher dNBR values are evidence of more severe effects of fire (i.e., a greater loss of aboveground vegetation). This assumption has been tested and supported by the analysis of data collected from several thousand field sites visited over the last decade [21]. Using this foundation, skilled analysts interpret the dNBR image to categorize burn severity into five thematic classes: High, Moderate, Low, Unburned to Low, and Increased Greenness (areas with more vegetation after the fire). Using on-screen digitizing, analysts create a perimeter for each fire using the dNBR data sets and original Landsat imagery as a guide. The thematic burn severity image is then intersected with land cover and other thematic layers (administrative, water sheds, etc.) to generate burn severity statistics (e.g., number of acres of evergreen forest burned at high severity, or moderate severity, etc.). Metadata are generated for each fire, including information about fire date and size, imagery used, and thresholds chosen. Finally, the inputs and results for each fire assessment are bundled and made available via the internet. For additional information and data download, see: http:/mtbs.gov or http://mtbs.cr.usgs.gov/viewer . 

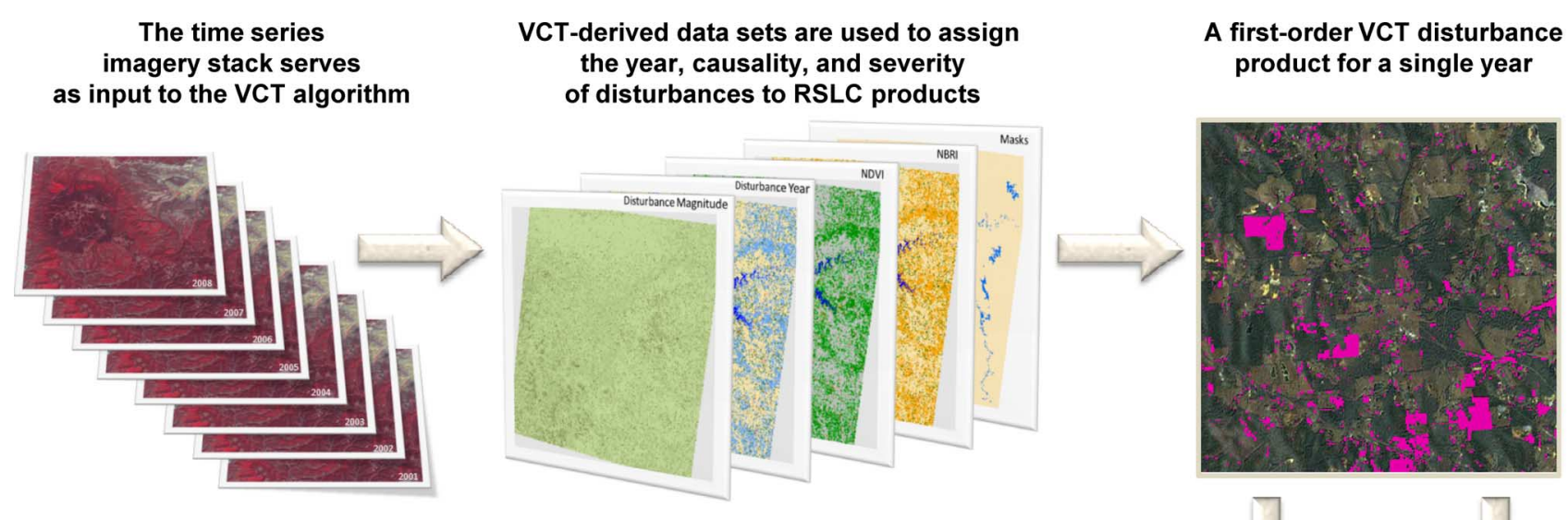
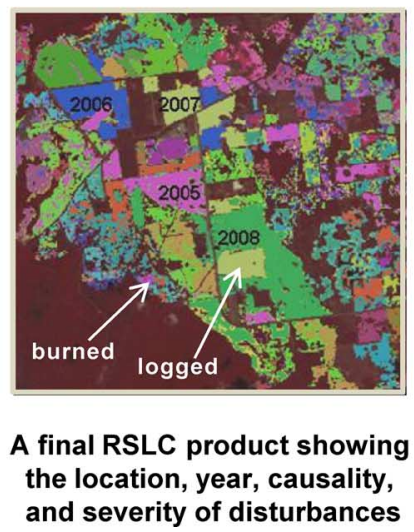
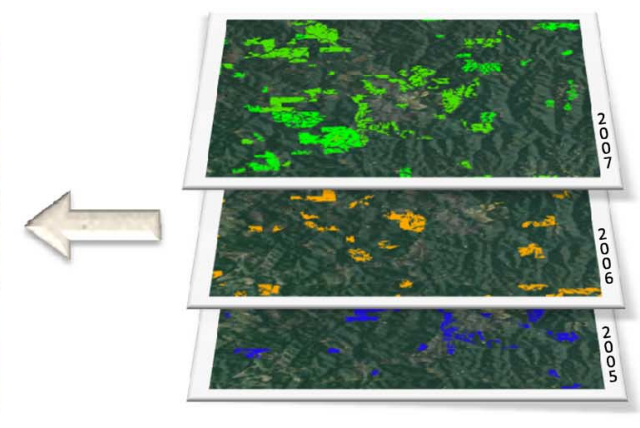

Cleaned disturbance images from each year are stacked to produce the final RSLC product

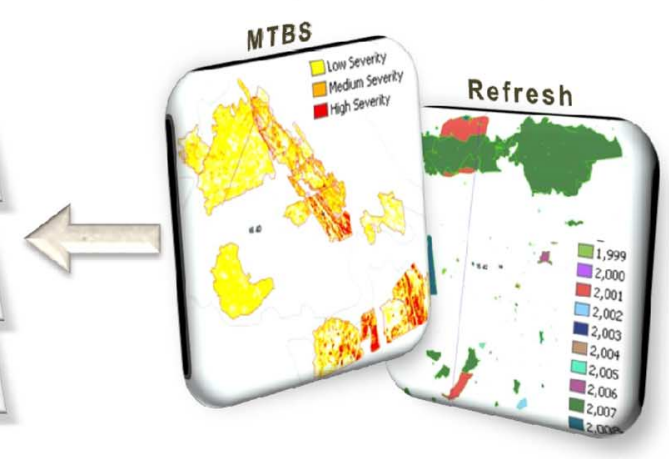

MTBS and Refresh data are used to assign/refine causality labels to the single year disturbance products

Fig. 4. An abridged representation of the process for creating Remote Sensing of Landscape Change products.

\section{The VEgEtation CHANGE TRACKER}

\section{A. General Overview}

The overall LANDFIRE mapping effort began over five years ago using circa 2000 vintage Landsat imagery. Both the users of the data as well as project management understood that an effort would be needed to bring the LANDFIRE data up-todate in order to retain relevancy and value. An effort known as "Refresh" was initiated to make the data more current and applicable to the user community. "Rapid Refresh" was the first component of the Refresh update strategy, and was completed in June 2008. This effort focused on quickly updating LANDFIRE data products in areas affected by recent (1999-2008) wildland fire disturbances using MTBS data. A more comprehensive effort utilizing both the MTBS and the LANDFIRE Events database is currently underway. While this information has become an important part of RSLC, it became apparent early on that we needed a more automated and "global" process for mapping and incorporating disturbance information. This led to the development of the Vegetation Change Tracker (VCT).

\section{B. Vegetation Change Tracker}

The VCT is an automated and highly efficient algorithm for mapping changes in forest cover. The algorithm uses Landsat time series stacks (LTSS), which are defined as sequences of
Landsat images with a nominal temporal interval (e.g., one image every year or every two years) for a particular location. LTSS images have been geometrically corrected to achieve subpixel geolocation accuracy and have high levels of radiometric consistency achieved using best available calibration coefficients and calculation of reflectance [9]. The VCT first converts the LTSS images into spectral indexes that are measures of the likelihood of each pixel being a forest pixel and then tracks these indexes over time. Changes are detected by looking for sharp decreases in forest likelihood as reflected by these indices. Fig. 4 shows the primary processes for creating RSLC products using VCT in a simplified diagram.

A major strength of the VCT process is that it enables the processing of an unprecedented amount of Landsat data to derive the change/disturbance products. Landsat imagery dating back to 1984 and up to 2009 (preferably one scene for every year) is compiled into stacks referred to as Landsat time series stacks (LTSS; Fig. 4). These stacks are compiled for every Landsat World Reference System (WRS) path/row falling within the conterminous United States. A LTSS can consist of up to 28 Landsat images, and we estimate that over 30,000 Landsat images will be utilized for mapping the conterminous US. The images used are generally $90 \%$ cloud-free and are geometrically referenced to the Albers Equal Area projection and converted to at-sensor reflectance. The principle of the VCT algorithm is 
(a)

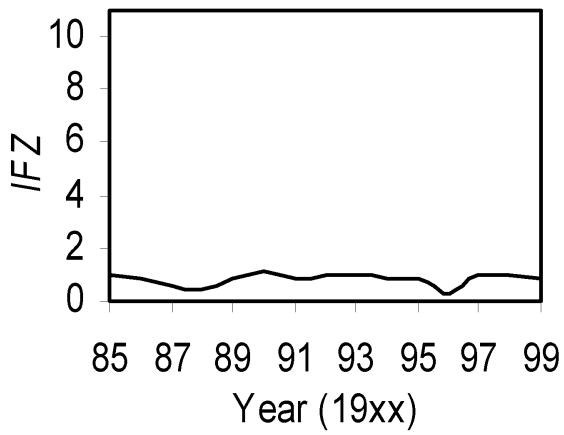

(c)

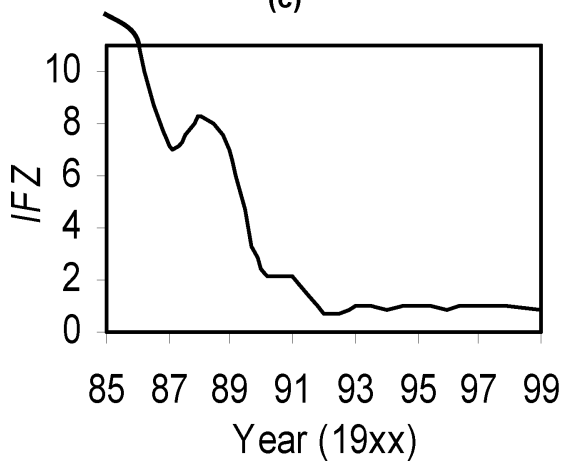

(b)

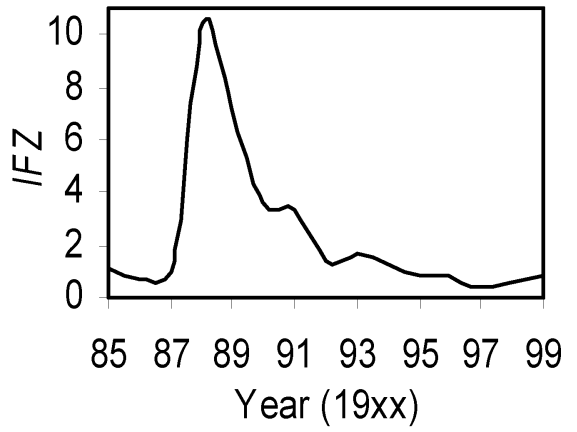

(d)

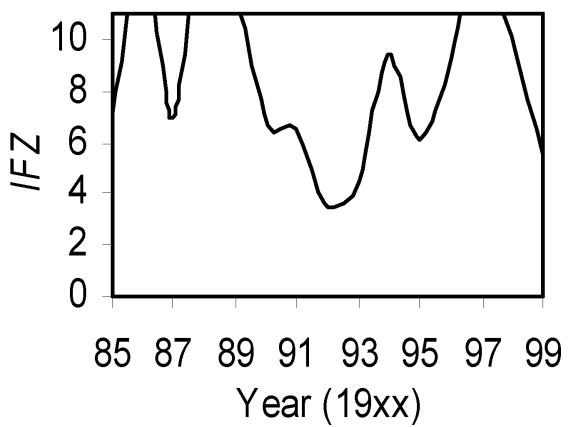

Fig. 5. Typical integrated forest $z$-score (IFZ) temporal profiles of major forest cover change processes (a-c) and non-forest (d) that are used to characterize different change processes. From [9]. (a) Persisting forest. (b) Forest disturbance. (c) Afforestation. (d) Persisting non-forest.

based on the following known properties of forest, disturbance, and post-disturbance recovery processes [9]:

- During the growing season, forest is one of the darkest vegetated surfaces in satellite images in many spectral bands [25]-[27].

- Undisturbed, naturally growing forests typically have relatively stable spectral signatures from one year to another.

- A disturbance generally results in an abrupt spectral change;

- Depending on the nature of the disturbance, the resultant change signal in the spectral data can last several years or longer. For disturbances followed by post-disturbance recovery, it takes many years for trees to reestablish, while a conversion of forest to non-forest land uses will result in non-forest signals in the years following the change.

The VCT algorithm works by simultaneously evaluating all observations provided by a LTSS for each pixel and determines the land cover and change process for that pixel based on its spectral-temporal properties. The algorithm consists of two major processes. The first is individual image masking and normalization. In this step each image is analyzed independently to create a mask in which confident forest pixels are identified. In addition, water, cloud, cloud shadow, cloud edge, and snow are flagged and output as a mask image. The established confident forest pixels are then used as a reference to normalize all pixels in that image and several indexes (which are measures of the likelihood of those pixels being forest pixels) are calculated. Once this step is complete for all images of a LTSS, the derived indices, as well as the masks, are used in a time series analysis process to produce forest change products.
The time series analysis of forest cover is used to determine change and non-change classes, and to derive a suite of attributes for characterizing the detected changes. It is based primarily on the physical interpretation of the integrated forest $z$-score (IFZ) [9]. In short, the IFZ measures the likelihood of a pixel being a forest pixel; its value should change in response to forest change. Fig. 5 shows typical temporal profiles of the IFZ for major land cover and forest change processes. For persisting forest land where no major disturbance occurred during the years being monitored the IFZ value stays low and is relatively stable throughout the monitoring period [Fig. 5(a)]. A significant increase in the $I F Z$ value indicates the occurrence of a disturbance in that year. A sequence of gradually decreasing $I F Z$ values following that disturbance represents the regeneration process of a new forest stand [Fig. 5(b)]. Conversion from non-forest to forest (afforestation) or regeneration of a forest stand from a disturbance that occurred before the first LTSS acquisition is identified by the gradual decrease of the IFZ from high values to the level of undisturbed forests [Fig. 5(c)]. Finally, Fig. 5(d) shows persisting non-forest as high and variable throughout the time series. While certain crops may be spectrally similar to forest and can have low $I F Z$ values during certain seasons, their $I F Z$ values likely will fluctuate as surface conditions change from one year to another due to harvest and crop rotation.

To further illustrate the application of the IFZ we have included a time series of Landsat image subsets showing a disturbance occurring between 1989 and 1990, which later regenerates back into full-canopy forest (Fig. 6). The plus (+) sign indicates the location of the $I F Z$ values plotted on the graph below the images. Note how the persisting forest shows consistent low 


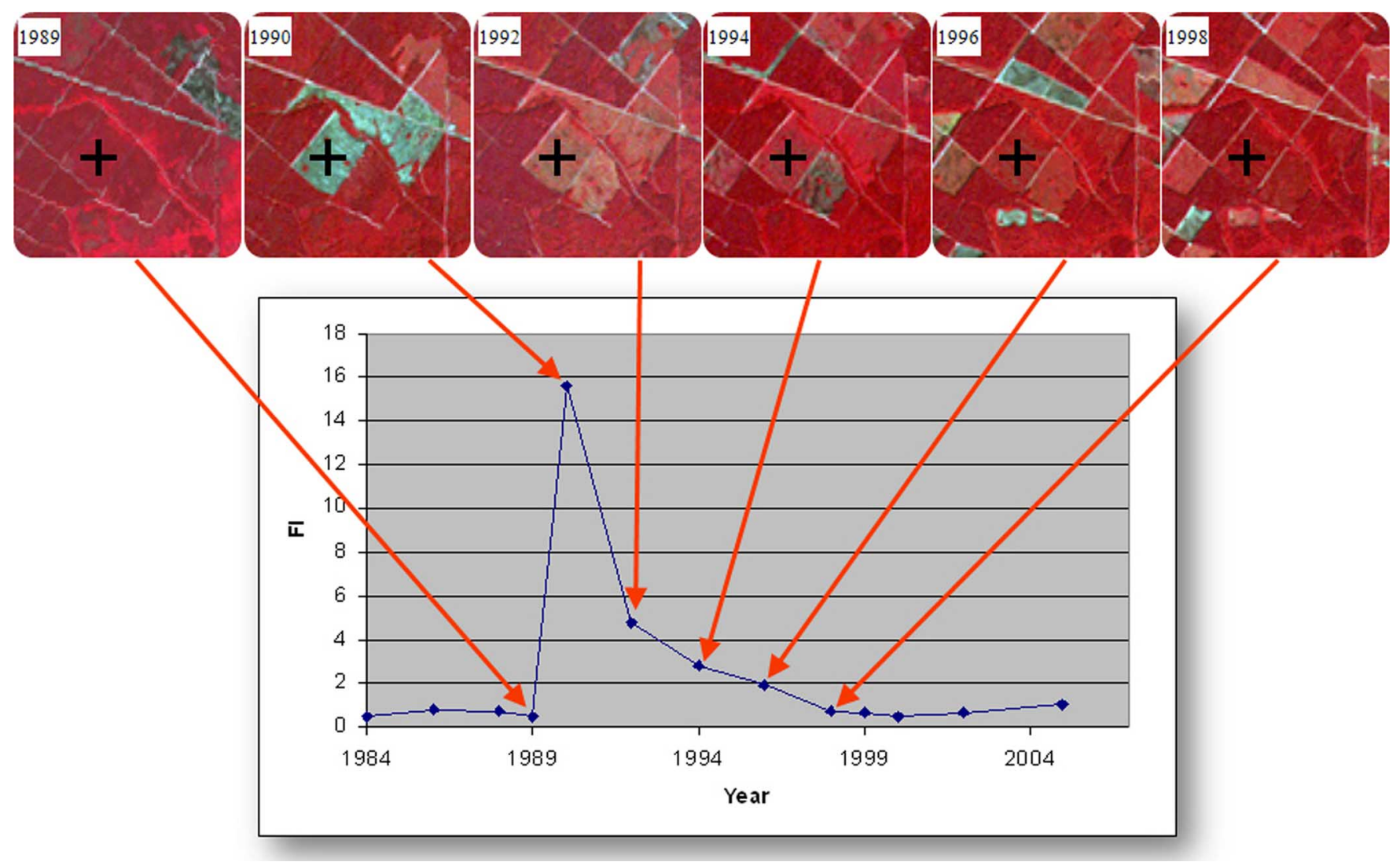

Fig. 6. A visual representation of how the Vegetation Change Tracker algorithm detects a forest disturbance.

values leading up to 1989 (indicating persisting forest), after which, a disturbance (clear cut) occurs. The IFZ values jump sharply between those two years and then slowly return back to a consistent trend of low values approximately nine years following the disturbance.

For each disturbance detected by the VCT, a disturbance year and several disturbance magnitude measures are calculated to characterize that disturbance. These measures are output as spatial products. It should be noted that first-order change products only indicate if and when a disturbance occurred. Determining the cause and severity of the disturbances are completed in subsequent processes as described in the following step.

\section{Vegetation Change Tracker Product Attribution and Cleanup}

A final RSLC product must not only show where the disturbances occurred, but also indicate a date of disturbance (to the nearest year), a cause of disturbance (referred to as causality), as well as the severity of the disturbance. Combinations of VCT output products (disturbance magnitude, disturbance year, burn ratios, etc.) are used in conjunction with other multi-temporal data sources such as those from Monitoring Trends in Burn Severity (MTBS) and the LANDFIRE Events database to infuse the necessary attributes into a final change product. This entire process is shown in Fig. 4.

Disturbance date is assigned to a change product by analyzing the "Year of Disturbance" data set - a standard VCT product. For a typical forest disturbance, the $I F Z$ value increases sharply following a consecutive period of low IFZ values [Fig. 5(b)]. While the actual occurrence of the disturbance is somewhere between the acquisition dates of the two consecutive images that show the sharp increase, disturbance year is defined by the acquisition year of the later image. In cases where an image gap occurs, the year of disturbance year could be late by the number of years between the two images. Having one image for each year of analysis would eliminate this issue, but acquisition of at least one good scene for each path/row every year is not assured due to issues of cloud cover and image quality.

Disturbance magnitude refers to the spectral change resulting from a disturbance. The VCT calculates three disturbance magnitudes with the first using the IFZ, the second using the Normalized Difference Vegetation Index (NDVI), and the third using the Normalized Burn Ratio (NBR) [9]. These disturbance magnitude products are used (either individually, or in combination) to derive regional severity of change information, whereby severity is attributed as three classes (high, medium or low). Severity levels are developed through interactive assessment using standard deviation information from the disturbance magnitude products.

Assigning causality is the final attributing activity, and this is largely a "hands-on" process. In the majority of cases the VCT changes are assumed to be related to forest cutting activity. Other possible disturbances include fire, insects and disease, or blow down. To determine if any of these latter disturbances are a factor, we rely on ancillary data sources such as the MTBS or the LANDFIRE Events database. While the VCT 


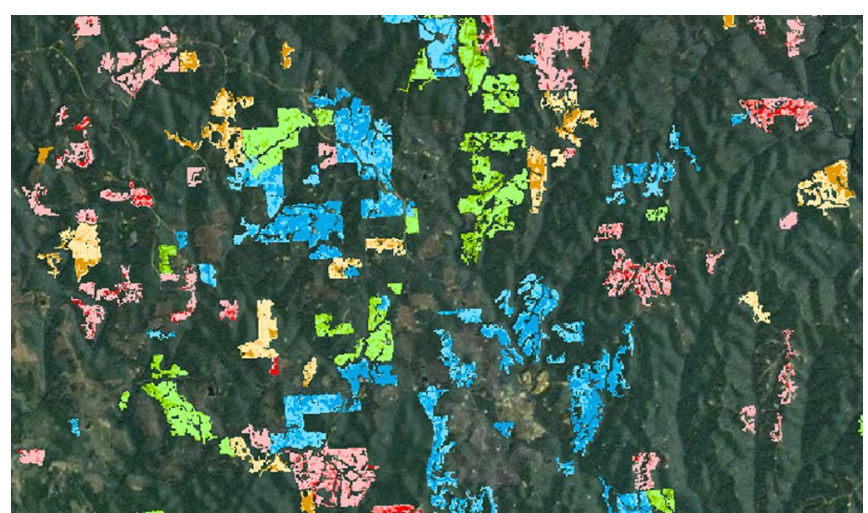

Fig. 7. A representation of a finalized VCT-derived disturbance product showing forest clearing disturbances near Samantha, AL. The color shades represent the year of disturbance $(\mathrm{red}=2000$, blue $=2001$, green $=2002$, and orange $=2003$ ), whereas the color intensity represents the severity of change (lighter color represents less severe disturbance).

process captures many of the more severe types of forest change (e.g., clear cutting, high severity fire), it is not as effective at capturing the more subtle types of change (e.g., thinning, prescribed fire), especially in non-forested ecosystems. In these cases the LANDFIRE Events data help to supplement the VCT change information by providing the spatial location and extent of these lesser-detectable disturbances. Additionally, analysts spend a notable amount of time analyzing the various input images and their associated VCT-derived datasets (such as NBR and NDVI) to help determine and/or refine the disturbance causes. Causality determination is a current area of interest and research.

Because VCT change products are computed pixel by pixel, the first-order output products are usually replete with single-pixel (or small groupings of pixels) disturbances (Fig. 4). LANDFIRE managers determined that disturbed areas of fewer than 50 contiguous pixels (approximately 4.5 ha) as too small for the purposes of large area updating. Therefore, before the attributed RSLC product is complete it must be "cleaned" by removing the "unwanted" disturbance pixels. The cleaning process is accomplished by using standard image processing techniques where clusters of pixels are verified as having either greater than 49 or less than 50 contiguous pixels. If there are fewer than 50 contiguous pixels they are purged.

\section{Final RSLC Product}

As a final step the data are examined for possible mapping inaccuracies or other possible errors through visual inspection or analyst-driven processing. In many cases, heads-up editing using standard image processing tools are used to remove errors and/or make final adjustments to the data. The final RSLC product is a stack of thematic raster layers where each layer represents a year of disturbance with severity and causality attributed to each disturbance pixel. Our first goal for LANDFIRE updating is to generate change data from 1999 through 2009 , but ultimately our plans are to generate annual change information dating back to 1984. A subset of a final RSLC product is shown in Fig. 7. This product then becomes a baseline product used to update other LANDFIRE data sets (e.g., existing vegetation) through use of successional modeling and related techniques.

\section{INSECTS AND DISEASE}

\section{A. General Overview}

As described earlier in this paper, we have made significant headway in terms of developing approaches for monitoring major land cover changes related to logging and fire. However, there are also many more subtle "within-state" changes occurring across landscapes, including those related to insect damage, wind, pollution, climate and succession. These types of changes tend to be relatively difficult to detect and to assign causality using remote-sensing technology. Nonetheless, the cumulative impacts of these types of "subtle" changes can have substantial impacts on various ecosystem processes, and result in changes in carbon balance, biogeochemical cycling, microclimate, patterns of biodiversity, and fire [28]-[31].

There are a number of reasons why detection and monitoring of gradual ecosystem change using remote sensing technology can be problematic. In the past, such assessments could be hindered by the cost of the data. With free access to the Landsat data archive, as well as access to various derived Moderate Resolution Imaging Spectroradiometer (MODIS) and Advanced Very High Resolution Radiometer (AVHRR) products, this problem should be alleviated. Other issues that have mired research of gradual ecosystem change include, but are not limited to, the following: 1) insufficient understanding of normal spectral conditions and variability, which compromises our ability to detect "abnormal" spectral conditions; 2) availability of adequate field information to aid analytical processes; and 3) lack of image data acquired at appropriate times. In spite of these difficulties, successful investigations using remote sensing for detecting and monitoring subtle and gradual within-state changes have been reported [32]-[34]. For updating LANDFIRE data sets, we will focus primarily on identifying disturbances related to major within-state changes. Some of the more obvious examples include major insect outbreaks, such as those caused by the mountain pine beetle, spruce budworm, and gypsy moth [35]-[37].

\section{B. Methodology for Detecting Insect and Disease Damage}

One of the difficulties of developing operational methodology for assessing insect damage is that the spectral responses differ depending upon insect species and host species. As an example, the western spruce budworm is a defoliator [38], and the defoliation caused by the budworm is a multi-year event. While most trees can withstand single defoliation events, mortality will occur after repeated defoliation over successive years. Such repeated defoliation will cause gradual changes in the health of the conifer tree species affected. Conversely, the mountain pine bark beetle is a borer, and infestations caused by this insect impact the trees rapidly with a predictable series of green to red to grey vegetation color phases [39], [40]. Mortality caused by pine borers can be very rapid following the initial outbreak, and thus the spectral changes of the conifer tree canopies can similarly be very rapid following outbreak. We do not believe that development of a single approach for mapping and monitoring damage caused by a variety of insects impacting a wide variety of tree species is likely. Rather, we believe that it will be better to employ a suite of methods for assessing insect damage, and 

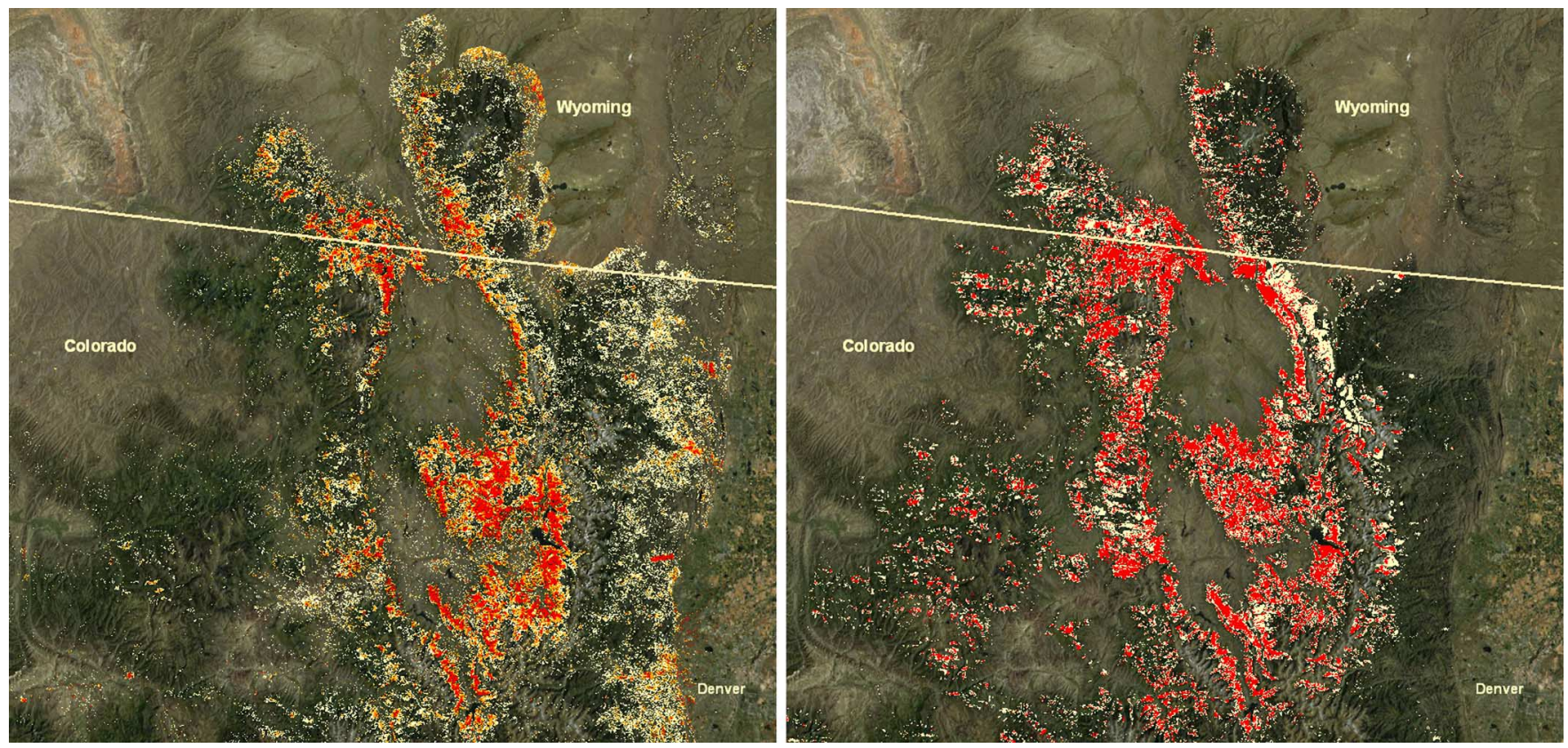

Fig. 8. Comparison between MODIS-derived NDVI difference images between 2003 and 2008 (left) and insect damage mapped by the Forest Health Monitoring Program in the southern Rocky Mountains of Colorado and Wyoming. In the left image, red indicates the largest seasonal NDVI decrease, orange represents moderate NDVI decreases, and white indicates low NDVI decreases. In the Forest Health Monitoring data (right), red indicates where insect damage was mapped in three or more years, whereas white represents areas mapped as insect damage in two years.

that the particular approach employed will be specific to the insect and the trees involved.

In previous work, we have demonstrated several different approaches that appear promising for operational insect damage mapping and monitoring. In one study, we were able to use Landsat time series data for mapping the multiple defoliations caused by the western spruce budworm [36]. The general approach employed included the following: 1) acquisition of a multi-year Landsat time series data set (preferentially selecting for late summer and early autumn scenes); 2) generating regression statistics of time versus spectral index for each pixel in the time series; 3) developing spatial data layers depicting the statistics, including slope and statistical significance of the time versus spectral index relationship; and 4) comparing with spatial insect damage information acquired aerially by the Forest Health Monitoring program (FHM) [41] to verify that the patterns developed from the imagery were reasonable. This particular approach can be especially appropriate for detecting, mapping and monitoring gradual changes taking place over multiple years. For this approach to work it is important that remotelysensed data be normalized in some manner, such as conversion to at-sensor reflectance. Selection of the appropriate spectral index will depend upon the perturbation being investigated, but in the case of western spruce budworm, both Short-wave/Near infrared index (SWIR/NIR) [42], [43] and Normalized Difference Vegetation Index (NDVI) were found to be useful. While the latter was not as effective as the former, both were shown to work.

In assessments of pine beetle damage, the regression approach that worked well for detecting western spruce budworm did not work, largely because the damage caused by this particular insect is rapid and gradual spectral change is not characteristic of mountain pine beetle damage. However, we did find that traditional "before-after" difference data images produced using either NDVI or SWIR/NIR differences captured the damage quite well. We also found another approach to be particularly useful, which includes the following: 1 ) acquisition of biweekly or weekly MODIS-derived NDVI composites [44] from throughout multiple growing seasons (e.g., 2000 through 2008); 2) generating the median NDVI value for each year's growing season for each pixel; 3) deriving images that depict deviations from the median NDVI values for each pixel; and 4) comparing reference information, such as that acquired by the FHM program. An image depicting MODIS-derived change information in an area experiencing significant mountain pine beetle damage is shown in Fig. 8 adjacent to insect damage information provided by FHM. In this case, general patterns between MODIS change and FHM are reasonably similar, although MODIS detected a number of "changes" not mapped as damage by FHM. One of our caveats regarding use of MODIS data (and other sources of remotely-sensed data) for change assessments is that seasonality and phenology can have marked influences on remotely-sensed signals, and that it can be difficult to separate the changes that we are interested in mapping (in this case insect damage) from other types of change (e.g., seasonality), and that we need to be cautious in interpreting spectral changes. In Fig. 8, the most significant MODIS spectral changes are related to the pine beetle damage, and in general we believe that MODIS data should be very useful for capturing US-scale interannual patterns of insect damage. At the same time, we strongly suspect that some of the changes in Fig. 8 (most notably in the eastern part of the MODIS-derived change product) are related to seasonality issues, and we need a way to reduce "false alarms" related to 
these types of events. Nonetheless, we believe that the MODIS data were effective in depicting insect damage, and we believe that the similar approaches, using other sensors such as the Landsat TM, and using other indices, such as the SWIR/NIR, will also be effective in detecting pine beetle damage. It is noteworthy that while the spatial resolution of the MODIS is much coarser than TM/ETM+ $(250 \mathrm{~m}$ for visible and NIR channels of MODIS versus $30 \mathrm{~m}$ for Landsat TM/ETM+), the high temporal frequency of MODIS data acquisitions helps to compensate for the spatial resolution issues. The generation of weekly and biweekly composites from MODIS data [44] facilitates the use of the data, making inter-annual comparisons much more routine, which is one step closer to operational monitoring. As yet, insects and disease information has not been incorporated into the RSLC, but the long range plans include doing so.

\section{CONCLusions: Future Research OpPortunities AND CHALLENGES}

\section{A. General Overview}

One of the major values of LANDFIRE is that it provides consistent and complete spatial products of the United States relevant to many regional to national scale applications [2]. A major challenge for us will be not only to keep the data sets current, but also to be able to do this in an efficient and cost effective manner. At present, our goal is to update the land cover data sets on an annual to biennial basis. While we have made good progress towards meeting this goal, there are a number of technical challenges facing us, and we anticipate that we will need to continue refining the process in the foreseeable future. Following are a few key areas that we believe will be important research topics for us over the next several years.

\section{B. Alternative Sources of Remotely-Sensed Data}

Both Landsat 5 and Landsat 7 missions are well beyond their design lives, and could malfunction at any time. The successor to Landsats 5 and 7 is planned for launch in December 2012, and thus it is possible that we could have a Landsat data gap in the near future. This would adversely impact all aspects of LANDFIRE updating. We are currently in the process of identifying and evaluating potential alternative data sources of satellite imagery for updating LANDFIRE data sets. Some previous studies [45], [46] have made headway towards using some of these alternative sensors for filling a potential data gap. From our own work, it appears that the spectral and radiometric properties of AWiFS are very suitable for updating LANDFIRE data sets. From our analyses, we believe that we will be able to inter-calibrate AWiFS and Landsat data, and be able to use one source of information to replace the other, if necessary.

\section{Structure Mapping}

Landsat data can provide extensive spatial coverage of forest structure in the horizontal dimension and are useful for canopy percentage cover estimation. However, these data sets are relatively insensitive for assessing the vertical dimension. Thus, forest canopy height, which is an important variable for modeling fire fuel, has been a challenge to quantify adequately for the LANDFIRE project. With the development of new sensors such as Lidar and InSAR, new data fusion methods have demonstrated improvements in canopy height estimation [47], [48] . Further investigation and application of these methods on the national scale will bring in a revolution of canopy height mapping for the next generation LANDFIRE products. Once a good canopy height data layer is developed for any given point in time, we will be able to incorporate VCT-derived change information, and model ensuing height changes based on canopy growth models.

\section{Development of Automatic Methods for Assigning Change Causality}

While the VCT is very good at detecting forest changes that have taken place, the algorithm does not assign causality to the changes. Thus, we know what has changed, but not necessarily what it has changed to. The types of changes can have large effects on fire fuel. As an example, a harvested forest will have different fire fuel conditions than a similar forest burned by wildfire. In addition, the two will have different growth trajectories that will also modify fire fuel conditions. Thus, far during our updating process, we have spent a lot of time assigning causality, and much of this work has been done using largely manual methods. As yet, we do not have an easy way to assign causality to changed pixels. Automatic or semi-automatic assignment of causality of these changes is a topic that we are beginning to explore. We envision that assessments that include regional-based assessments of change, such as FIA and UGSS Trends data [49], when used in conjunction with the VCT data output, will facilitate the labeling process.

\section{E. Extending MTBS Data Using Multispectral Scanner Data}

Currently, MTBS has been characterizing wildland fire mostly using Landsat TM and ETM+ data. Indexes that use the shortwave infrared (TM band 7) tend to be better at characterizing burn severity than indexes that do not use this spectral region, such as the NDVI. Nonetheless, the NDVI can be useful for mapping at least general wildand fire and severity characteristics. We would like to add to the MTBS baseline by including assessments derived from Multispectral Scanner (MSS) data collected from 1972 through 1984. MSS data do not have the spatial resolution of the TM/ETM+ sensors, nor do they have the radiometric fidelity or spectral resolution of the more advanced sensors. Despite these limitations, we believe that MSS data will be useful for providing general fire trends that occurred during this time period, which will help put the more recent fires into a better historical context.

\section{F. Data Availability}

For VCT to work effectively, good time series data, either at annual or biennial intervals, are advantageous. It is also important that individual data sets being analyzed within the LTSS represent similar phenological conditions. Unfortunately, many parts of the country are very cloudy, and acquisition of good quality data meeting these requirements is not guaranteed. One possible solution is to use composite images comprised of the "best pixel" for a given scene representing a particular time period. For instance, if several partly cloudy scenes are the best 
data sets for summer of a particular year, we can use various compositing approaches to "create" a good data set for that time period to use in the LTSS. Previous studies [50]-[52] have demonstrated that such composites can be generated efficiently and consistently, and hold much promise for filling potential gaps in data sets. As a corollary to this, we do not believe that we will be able to use the VCT approach for Alaska or Hawaii, due to a paucity of available data sets to create a good LTSS. For these areas, we will likely need to use MODIS data to generate time series information. The best approaches for incorporating MODIS data into the LANDFIRE updating process has not been worked out yet.

\section{G. Other RSLC Research Topics}

While VCT has been shown to be very effective at mapping changes related to forest harvesting, additional refinement needs to be done so that it is also effective in non-forested environments. Much of the western United States is shrubland, and many of these areas burn frequently and are of great concern to natural resource managers. Currently the characterization of these areas using VCT has had mixed success. Additional work will need to be done to spectrally characterize nonforested changes, and then this information will need to be incorporated into the VCT algorithm.

\section{H. Final Thoughts}

Developing a nationwide operational terrestrial monitoring system using remotely-sensed data sets requires significant commitment and resources. While developing national wall-to-wall land cover change data sets has been a priority for many groups over the last several decades [53], [54], we are just now at the point where we are beginning to implement these goals. There are still significant challenges ahead of us, but we believe that the research community as a whole is making great strides towards developing such a system. While the work described in this paper has a strong focus on disturbance processes related to LANDFIRE, we believe that the RSLC data sets described will have application to a broader community.

\section{ACKNOWLEDGMENT}

The authors thank personnel of the Department of the Interior, Office of Wildland Fire Coordination, U.S. Forest Service Office of Fire and Aviation Management, and Science and Application Branch of the Center for Earth Earth Resources Observation and Science (EROS). Additionally, the authors thank L. Yang and G. Xian for helpful reviews of a previous version of this manuscript.

\section{REFERENCES}

[1] The National Fire Plan, NFP, 2009 [Online]. Available: www.healthyforestsandrangelands.gov

[2] The LANDFIRE Charter, USDA and DOI, 2004 [Online]. Available: www.landfire.gov/

[3] M. G. Rollins, "LANDFIRE: A nationally consistent vegetation, wildland fire, and fuel assessment," Int. J. Wildland Fire, vol. 18, no. 3, pp. 235-249, May 2009.

[4] C. Homer, J. Dewitz, J. Fry, M. Coan, N. Hossain, C. Larson, N. Herold, A. McKerrow, J. N. VanDriel, and J. Wickham, "Completion of the 2001 national land cover database for the conterminous United States," Photogrammetric Engineering and Remote Sensing, vol. 73, no. 4, pp. 337-341, Apr. 2007.
[5] J. R. Quinlan, C4.5: Programs for Machine Learning. San Mateo, CA: Morgan Kaufmann, 1993.

[6] P. Comer, D. Faber-Langendoen, R. Evans, S. Gawler, C. Josse, G. Kittel, S. Menard, M. Pyne, M. Reid, K. Schulz, K. Snow, and J. Teague, Ecological Systems of the United States: A Working Classification of US Terrestrial Systems. Arlington, VA: NatureServe, 2003.

[7] C. Homer, C. Huang, L. Yang, B. Wylie, and M. Coan, "Development of a 2001 national landcover database for the United States," Photogrammetric Engineering and Remote Sensing, vol. 70, no. 7, pp. 829-840, Jul. 2004.

[8] C. E. Woodcock et al., "Free access to Landsat imagery," Science, vol. 320, no. 5879, p. 1011, May 2008.

[9] C. Huang, S. N. Goward, J. G. Masek, N. Thomas, Z. Zhu, and J. E. Vogelmann, "An automated approach for reconstructing recent forest disturbance history using dense Landsat time series stacks," Remote Sensing of Environment, 2009, DOI:10.1016/j.rse.2009.08. 017.

[10] C. Toney, M. Rollins, K. Short, T. Frescino, R. Tymcio, and B. Peterson, R. E. McRoberts, G. A. Reams, P. C. Van Deusen, and W. H. McWilliams, Eds., "Use of FIA plot data in the LANDFIRE Project," in Proc. 7th Annu. Forest Inventory and Analysis Symp., Portland, ME, Oct. 3-6, 2005, pp. 309-319.

[11] D. C. Lutes, R. E. Keane, J. F. Caratti, C. H. Key, N. C. Benson, S. Sutherland, and L. J. Gangi, FIREMON: Fire Effects Monitoring and Inventory System, U.S. Department of Agriculture, Forest Service, Rocky Mountain Research Station, Fort Collins, CO, Gen. Tech. Rep. RMRS-GTR-164-CD, 2006.

[12] E. Reinhardt and C. L. Crookston, The Fire and Fuels Extension to the Forest Vegetation Simulator, U.S. Department of Agriculture, Forest Service, Rocky Mountain Research Station, Ogden, UT, Gen. Tech. Rep. RMRS-GTR-116, 2003.

[13] C. Toney, J. D. Shaw, and M. D. Nelson, W. McWilliams, G. Moisen, and R. Czaplewski, Eds., "A stem-map model for predicting tree canopy cover of Forest Inventory and Analysis (FIA) plots," in Proc. Forest Inventory and Analysis Symp. 2008, Park City, UT, Oct. 21-23, 2008, Proc. RMRS-P-56CD.

[14] C. Toney and M. C. Reeves, "Equations to convert compacted crown ratio to uncompacted crown ratio for trees in the Interior West," Western J. Applied Forestry, vol. 24, no. 2, pp. 76-82, Apr. 2009.

[15] E. Reinhardt, D. Lutes, and J. Scott, P. L. Andrews and B. W. Butler, Eds., "FuelCalc: A method for estimating fuel characteristics," in Fuels Management-How to Measure Success: Conf. Proc., Portland, OR, Mar. 28-30, 2006, pp. 273-282, Proc. RMRS-P-41.

[16] Elevation Derivatives for National Applications, USGS, 2005 [Online]. Available: http://edna.usgs.gov/

[17] State Soil Geographic (STATSGO) Database, USDA NRCS, 2005 [Online]. Available: http://www.ncgc.nrcs.usda.gov/products/datasets/statsgo/index.html

[18] S. W. Running and E. R. Hunt, "Generalization of a forest ecosystem process model for other biomes, BIOME-BGC, and an application for global scale models," in Scaling Physiological Processes: Leaf to Globe. Burlington, MA: Academic Press, 1993, pp. 141-157.

[19] R. E. Keane, M. G. Rollins, C. H. McNicoll, and R. A. Parsons, Predictive Landscape Modeling Using Gradient-Based Sampling, Remote Sensing, and Ecosystem Simulation, U.S. Department of Agriculture, Forest Service, Rocky Mountain Research Station, Fort Collins, CO, 2002, Gen. Tech. Rep. RMRS-GTR-92.

[20] J. Epting, D. Verbyla, and B. Sorbel, "Evaluation of remotely sensed indexes for assessing burn severity in interior Alaska using Landsat TM and ETM+," Remote Sensing of Environment, vol. 96, no. 3-4, pp. 328-339, Jun. 2005.

[21] C. H. Key and N. C. BensonD. C. Lutes, Landscape Assessment: Ground Measure of Severity, The Composite Burn Index, FIREMON: Fire Effects Monitoring and Inventory System, USDA Forest Service, Rocky Mountain Research Station, Ogden, UT, 2005, General Technical Report, RMRSGTR-164-CD:LA1-LA51.

[22] J. D. Miller and S. R. Yool, "Mapping forest post-fire canopy consumption in several overstory types using multi-temporal Landsat TM and ETM data," Remote Sensing of Environment, vol. 82, no. 2-3, pp. 481-496, Oct. 2002.

[23] A. Singh, "Digital change detection techniques using remotely-sensed data," Int. J. Remote Sensing, vol. 10, no. 6, pp. 989-1003, Jun. 1989.

[24] Glossary of Wildland Fire Terminology, NWCG, 2009 [Online]. Available: http://www.nwcg.gov/pms/pubs/glossary/index.htm

[25] J. E. Colwell, "Vegetation canopy reflectance," Remote Sensing of Environment, vol. 3, no. 3, pp. 174-183, Mar. 1974. 
[26] S. N. S. N. Goward, K. F. Huemmrich, and R. H. Waring, "Visiblenear infrared spectral reflectance of landscape components in western Oregon," Remote Sensing of Environment, vol. 47, no. 2, pp. 190-203, Feb. 1994.

[27] K. F. Huemmrich and S. N. Goward, "Vegetation canopy PAR absorptance and NDVI: An assessment for ten tree species with the SAIL model," Remote Sensing of Environment, vol. 61, no. 2, pp. 254-269, Aug. 1997.

[28] G. M. Lovett, C. D. Canham, M. A. Arthur, K. C. Weathers, and R. D. Fitzhugh, "Forest ecosystem responses to exotic pests and pathogens in eastern North America," BioScience, vol. 56, no. 5, pp. 395-405, May 2006.

[29] G. L. W. Perry and J. D. A. Millington, "Spatial modeling of succession-disturbance dynamics in forest ecosystems: Concepts and examples," Perspectives in Plant Ecology, Evolution and Systematics, vol. 9, no. 3-4, pp. 191-210, Mar. 2008

[30] M. G. Turner, "Landscape ecology: What is the state of the science," Annu. Rev. Ecology, Evolution and Systematics, vol. 36, pp. 319-344, Dec. 2005.

[31] T. J. Parker, K. M. Clancy, and R. L. Mathiasen, "Interactions among fire, insects and pathogens in coniferous forests of the interior western United States and Canada," Agricultural and Forest Entomology, vol. 8, pp. 167-189, Aug. 2006.

[32] R. D. Beck, R. S. Maxwell, V. H. Treat, and H. C. Dethloff, "Timeless Heritage: A History of the Forest Service in the Southwest," US Dept. Agriculture, Forest Service FS-409, 1988

[33] A. T. Roder, J. Hill, B. Duguy, J. A. Alloza, and R. Vallejo, "Using long time series of Landsat data to monitor fire events and post-fire dynamics and identify driving factors. A case study in the Ayora region (eastern Spain)," Remote Sensing of Environment, vol. 112, no. 1, pp. 259-273, Jan. 2008.

[34] S. M. Souza and D. Roberts, "Mapping forest degradation in the Amazon region with Ikonos images," Int. J. Remote Sensing, vol. 26, no. 3, pp. 425-429, Mar. 2005.

[35] W. A. Kurz, C. C. Dymond, G. Stinson, G. J. Rampley, E. T. Neilson, A. L. Caroll, T. Ebata, and L. Safranyik, "Mountain pine beetle and forest carbon feedback to climate change," Nature, vol. 452, no. 7190, pp. 987-990, Apr. 2008.

[36] J. E. Vogelmann, B. Tolk, and Z. Zhu, "Monitoring forest changes in the southwestern United States using multitemporal Landsat data," Remote Sensing of Environment, vol. 113, no. 8, pp. 1739-1748, Aug. 2009.

[37] K. M. De Beurs and P. A. Townsend, "Estimating the effect of gypsy moth defoliation using MODIS," Remote Sensing of Environment, vol. 112, no. 10, pp. 3983-3990, Oct. 2008.

[38] D. G. Fellen and J. E. Dewey, "Western spruce budworm," USDA Forest Service, Forest Insect and Disease Leaflet, vol. 53, 1982.

[39] L. E. Maclauchlin, J. E. Brooks, and J. C. Hodge, "Analysis of historic western spruce budworm defoliation in south central British Columbia," Forest Ecology and Management, vol. 226, no. 1-3, pp. 351-356, May 2006.

[40] M. A. Wulder, C. C. Dymond, J. C. White, D. G. Leckie, and A. L. Caroll, "Surveying mountain pine beetle damage of forests: A review of remote sensing opportunities," Forest Ecology and Management, vol. 221, no. 1-3, pp. 27-41, Jan. 2006.

[41] USDA, Nov. 2009 [Online]. Available: http://www.fs.fed.us

[42] J. E. Vogelmann and B. N. Rock, "Assessing forest damage in high-elevation coniferous forests in Vermont and New Hampshire using Thematic Mapper data," Remote Sensing of Environment, vol. 24, no. 2, pp. 227-246, Mar. 1988.

[43] J. E. Vogelmann, "Comparison between two vegetation indexes for measuring different types of forest damage in the northeastern United States," Int. J. Remote Sensing, vol. 11, no. 12, pp. 2281-2297, Dec. 1990.

[44] C. B. Jenkerson and G. Schmidt, W. T. Pecora, Ed., "eMODIS product access for large scale monitoring," in 17th Memorial Symp. Remote Sensing, Denver, CO, Nov. 16-20, 2008.

[45] G. Chander, "Initial Data Characterization, Science Utility and Mission Capability Evaluation of Candidate Landsat Mission Data Gap Sensors," Technical Report Landsat Data Gap Study, 2007 [Online]. Available: http://calval.cr.usgs.gov/LDGST.php

[46] M. A. Wulder, J. C. White, S. N. Goward, J. G. Masek, J. R. Irons, M. Herold, W. B. Cohen, T. R. Loveland, and C. E. Woodcock, "Landsat continuity: Issues and opportunities for land cover monitoring," Remote Sensing of Environment, vol. 112, no. 3, pp. 955-969, Mar. 2008.
[47] A. T. Hudak, M. A. Lefsky, W. B. Cohen, and M. Berterretche, "Integration of lidar and Landsat ETM+ data for estimating and mapping forest canopy height," Remote Sensing of Environment, vol. 82, no. 2-3, pp. 397-416, Oct. 2002.

[48] W. S. Walker, J. M. Kellndorfer, E. LaPoint, M. Hoppus, and J. Westfall, "An empirical InSAR-optical fusion approach to mapping vegetation canopy height," Remote Sensing of Environment, vol. 109, no. 4, pp. 482-499, Aug. 2007.

[49] T. R. Loveland, T. L. Sohl, S. V. Stehman, A. L. Gallant, K. L. Sayler, and D. E. Napton, "A strategy for estimating the rates of recent United States land-cover changes," Photogrammetric Engineering and Remote Sensing, vol. 68, no. 10, pp. 1091-1099, Oct. 2002.

[50] D. P. Roy, J. Ju, P. Lewis, C. Schaaf, F. Gao, M. Hansen, and E. Lindquist, "Multi-temporal MODIS-Landsat data fusion for relative radiometric normalization, gap filling, and prediction of Landsat data," Remote Sensing of Environment, vol. 112, no. 6, pp. 3112-3130, Jun. 2008.

[51] D. P. Roy, J. Ju, K. Kline, P. L. Scaramuzza, V. Kovalskyy, M. Hansen, T. R. Loveland, E. Vermote, and C. Zhang, "Web-enabled Landsat Data (WELD): Landsat ETM+ composited mosaics of the conterminous United States," Remote Sensing of Environment, 2009, DOI:10. 1016/j.rse.2009.08.011

[52] J. Ju and D. P. Roy, "The availability of cloud-free Landsat ETM+ data over the conterminous United States and globally," Remote Sensing of Environment, vol. 112, no. 3, pp. 1196-1211, Mar. 2008.

[53] "Facing Tomorrow's Challenges-U.S. Geological Survey Science in the Decade 2007-2017,' USGS, 2007, U.S. Geological Survey Circular $1309, \mathrm{x}+70 \mathrm{p}$.

[54] "Grand Challenges in Environmental Sciences," National Research Council, National Academy Press, Washington, DC, 2001.

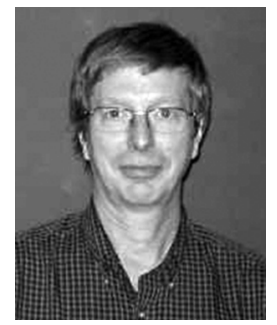

James E. Vogelmann received the Ph.D. degree in plant biology from Indiana University, Bloomington, IN.

He is a Research Ecologist at the USGS Center for Earth Resources Observation and Science (EROS). His research interests and publications focus on the use of Landsat data and other sources of geospatial information for mapping, characterizing and monitoring vegetation condition across large areas. He is currently a member of the Landsat Science Team.

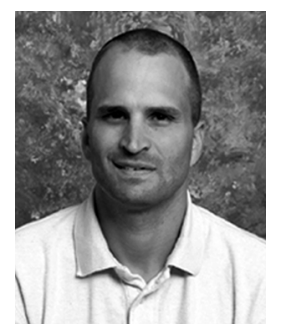

Jay R. Kost received the M.S. degree in space studies from the University of North Dakota, Grand Forks, $\mathrm{ND}$, in 1990.

He has been with the USGS EROS since 1997 and currently works as a Senior Scientist on the LANDFIRE project. His background includes multi-disciplinary work in spatial data management, land cover and change mapping, wetland science, and fire science.

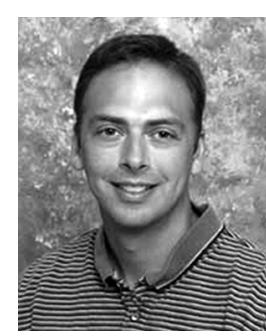

Brian Tolk received the M.A. degree in geography from the University of Nebraska, Lincoln, in 1996 specializing in remote sensing and GIS.

Working under various contractors, he has been employed at the USGS EROS, Sioux Falls, SD, since 1998. His research interests include landcover/land use, change detection, and remote sensing of water quality. 


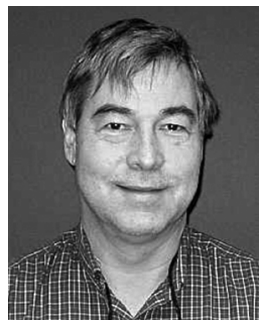

Stephen Howard received the M.S. degree in geography from the South Dakota State University, Brookings, SD, in 1984.

He has been at the USGS EROS since 1985. His research interests include vegetation mapping and monitoring using satellite data.

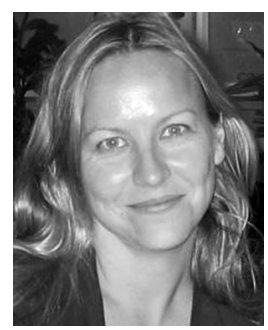

Karen Short received the B.S. degree in wildlife and fisheries science from the University of Arizona, Tucson, and the Ph.D. degree in organismal biology and ecology from the University of Montana, Missoula.

She is a Research Scientist with Systems for Environmental Management, Missoula, MT. She has conducted much of her research in conjunction with prescribed fires in southwestern national parks, studying responses of plants, insects, and birds, to the burns. She is currently the Reference Data Administrator for the national LANDFIRE Project on contract through the Missoula Fire Sciences Laboratory.

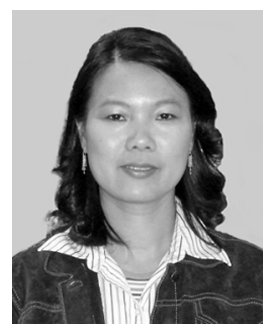

Xuexia Chen (A'08) received the Ph.D. degree in atmosphere, environment, and water resources from the South Dakota School of Mines and Technology, Rapid City, SD, in 2004.

She is currently a Senior Scientist with ASRC Research and Technology Solutions, contractor to USGS EROS. For the past ten years, she has been working on image relative normalization, spectral unmixing, burn severity detection, and fire combusted biomass estimation. She has been heavily and structure since 2004.

involved in mapping LANDFIRE existing vegetation

Dr. Chen is currently a member of the American Geophysical Union (AGU), the Sigma Xi, and the Institute of Electrical and Electronics Engineers (IEEE).

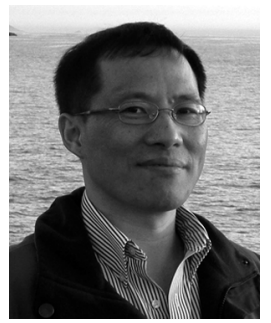

Chengquan Huang received the B.S. and M.S. degrees from Peking University, China, and the Ph.D. degree from the University of Maryland, College Park.

$\mathrm{He}$ is a member of the Research Faculty in the Geography Department of the University of Maryland. His research interests include characterization and monitoring of land cover, biomass, and ecosystem dynamics by integrating satellite and non-satellite observations.

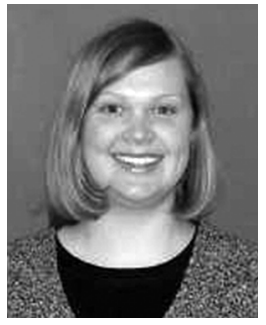

post-fire effects.
Kari Pabst received the B.A. degree in biology from Augustana College, Sioux Falls, SD, and will graduate with the M.S. degree in geography from South Dakota State University, Brookings, SD, in May 2010.

She is employed by ASRC Research and Technology Solutions as a contractor to the USGS EROS. She supports Fire Science and is currently working on the Monitoring Trends in Burn Severity Project. Her research interests include fire ecology and using remote sensing and GIS as tools to map and monitor

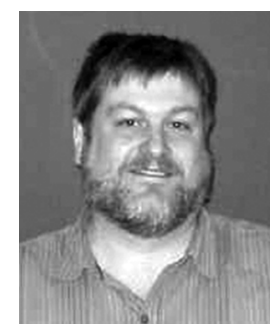

Matthew G. Rollins received the M.S. degree in forestry from the University of Montana, and the Ph.D. degree from the University of Arizona.

$\mathrm{He}$ is Wildland Fire Science Team lead at the USGS EROS in Sioux Falls, SD. His recent research has included assessing changes in fire and landscape patterns under different wildland fire management scenarios, relating fire regimes to landscape-scale biophysical gradients and climate variability, and developing predictive landscape models of fire frequency, fire effects, and fuel characteristics. 